Cita bibliográfica: García-Hernández, C., Ruiz-Fernández, J., Oliva, M., y Gallinar, D. (2018). El episodio de movimientos en masa asociado a los temporales de nieve de 1888 en el Macizo Asturiano. Boletín de la Asociación de Geógrafos Españoles, 76, 52-78. doi: 10.21138/bage.2515

\title{
El episodio de movimientos en masa asociado a los temporales de nieve de 1888 en el Macizo Asturiano
}

The mass wasting episode associated to the 1888 snowstorms in the Asturian Massif (Northwestern Spain)

\author{
Cristina García-Hernández \\ cristingar@hotmail.com \\ Departamento de Geografía \\ Universidad de Oviedo (España) \\ Jesús Ruiz-Fernández \\ ruizjesus@uniovi.es \\ Departamento de Geografía \\ Universidad de Oviedo (España)
}

\section{Marc Oliva}

oliva_marc@yahoo.com

Centro de Estudos Geográficos

Universidade de Lisboa (Portugal)

\section{David Gallinar}

davidgallinar@hotmail.com

Departamento de Geografía

Universidad de Oviedo (España) 


\title{
Resumen
}

Este estudio analiza un episodio de movimientos en masa generado en el contexto de una serie de temporales cuyas repercusiones se dejaron sentir en numerosos países europeos e incluso en la Costa Este de Estados Unidos, afectando también al norte peninsular y, muy especialmente, al territorio del Macizo Asturiano. En este ámbito el episodio consistió en cuatro temporales de nieve que se sucedieron entre el 14 de febrero y el 8 de abril de 1888, dando lugar a espesores nivales que alcanzaron los 9 m de espesor máximo en núcleos como Pajares (1000 m s.n.m.). El manejo de fuentes históricas en combinación con el trabajo de campo y las entrevistas realizadas entre la población, ha permitido esclarecer las circunstancias en las que algunos de estos eventos se dieron, estableciendo la tipología de 27 de los movimientos desencadenados y determinando que, el deslizamiento, fue el tipo de inestabilidad más común. Determinados condicionantes como la litología del sustrato y el abrupto relieve propio de las zonas más altas del Macizo, unidos a factores antrópicos como las modificaciones previamente realizadas en la topografía de determinadas áreas, influyeron en el desarrollo de los hechos. Sin embargo, los aportes de agua procedentes de la fusión nival, se muestran como el principal agente causal de este episodio de movimientos en masa en el que 28 eventos generaron daños materiales así como grandes retrasos en las comunicaciones, resultando fallecida una persona.

Palabras clave: movimientos en masa; fusión nival; nevadas; 1888; Macizo Asturiano.

\begin{abstract}
This paper analyzes an episode of 36 mass movements triggered during the 1888 blizzard. In the Asturian Massif this blizzard consisted in four consecutive snowstorms that happened between 14th February and 8th April 1888, generating snow accumulations with a depth ranging 2-9 m. Historical documents, fieldwork and testimonies to the contemporary residents, have allowed to reconstruct this episode; in 27 events the typology of movement has been defined, and the landslide was the most common one. Several factors as the lithology of the substratum, the steep topography of the Asturian Massif high areas, and ground alterations because of the anthropic action, were the main determinants. Nevertheless, the water supplies originated from the snowmelt seems to be the main causal agent of this episode, in which 28 events were responsible for material damage as well as great delays in communications, and one rockfall caused the death of one person.
\end{abstract}

Key words: mass wasting; snowmelt; snowstorm; 1888; Asturian Massif.

Agradecimientos: Cristina García-Hernández agradece el apoyo de la Fundación Alvargonzález que, mediante la concesión de la XXII Beca de Investigación Ramón de la Sagra, ha permitido el desarrollo inicial de esta investigación. Asimismo, agradece al Ministerio de Educación, Cultura y 
Deporte la concesión de una Ayuda para la Formación de Profesorado Universitario (FPU), de la cual disfruta en la actualidad.

\section{Introducción}

Una de las principales acciones geomorfológicas de la cubierta nival se produce a raíz de su deshielo, pudiendo llegar a constituir un hecho peligroso al ser causa frecuente de episodios de movimientos en masa rápidos - dejando a un lado las avalanchas de nieve-, en ámbitos de montaña de latitudes medias (Horton, 1945; DeGraff et al., 1984; Strömquist, 1985; Chleborad, 1997; Raetzo et al., 2002; Gokceoglu et al., 2005). Si bien las consecuencias socioeconómicas que pueden implicar los episodios de avalanchas de nieve son bien conocidas (Muntán et al., 2009; García-Hernández et al., 2014; Podolskiy et al., 2014), episodios de movimientos en masa -deslizamientos, flujos, desprendimientos rocosos-, ligados en mayor o menor medida a la dinámica nival, pueden tener un gran impacto en términos de pérdidas personales y materiales (Schuster, 1996; Gokceoglu et al., 2005).

En la Península Ibérica, los efectos geomorfológicos de la fusión de la cubierta nival y, más concretamente, su capacidad de alterar la estabilidad de los taludes en áreas de alta montaña, han comenzado a ser estudiados en las tres últimas décadas (Vadillo, 1987; Gómez et al., 2002; Serrano y González-Trueba, 2004; Tanarro et al., 2010; Valcárcel y Carrera, 2010). En el territorio del Macizo Asturiano se ha prestado especial atención a la relación entre lluvias intensas y movimientos en masa rápidos (Domínguez-Cuesta et al., 1999; Jiménez Sánchez et al., 1999; Domínguez-Cuesta et al., 2007). Los efectos de la fusión nival sobre los movimientos de ladera, se han abordado en el contexto de la alta montaña, más concretamente en el ámbito de los Picos de Europa (Serrano y González-Trueba, 2004; González-Trueba y Serrano, 2010; Ruiz-Fernández et al., 2014; Ruiz-Fernández, 2015). Sin embargo, los trabajos citados se centran esencialmente en la morfodinámica actual de la alta montaña.

Este estudio aborda un episodio de movimientos en masa generado en el Macizo Asturiano en un contexto en el que, durante varias semanas, se sucedieron una serie de situaciones sinópticas propicias para el acaecimiento de importantes temporales de nieve en el Atlántico Norte. Las repercusiones de este fenómeno meteorológico se dejaron sentir en países europeos como Reino Unido, Francia y Suiza, así como en cinco estados de la Costa Este de Estados Unidos (Huschke, 1959; Kocin, 1983; Ericsson, 1991), afectando también al norte peninsular y, muy especialmente, al territorio del Macizo Asturiano en el que, además de los movimientos en masa, los temporales de nieve fueron capaces de generar avalanchas de nieve e inundaciones, causando más de 30 muertes y grandes daños materiales (García-Hernández et al., 2017, 2018). El análisis de un episodio histórico del que no se conservan sino recuerdos heredados - pues sucedió hace más de 
125 años- y escasas huellas físicas, hace indispensable la consulta de fuentes documentales entre las que destaca la prensa escrita. Los archivos de prensa han sido empleados con éxito en el estudio de la repercusión de diversos riesgos geomorfológicos en el pasado (Elliott y Kirschbaum, 2007; Devoli et al., 2007; Rossi et al., 2010; García-Hernández et al., 2014, 2017, 2018), pues proporcionan información abundante y regular. También los archivos parroquiales y municipales, a los que se ha recurrido en este trabajo, han sido utilizados por ejemplo para analizar el clima del pasado (Barriendos, 1997) o bien episodios de riesgo climático (Benito y Thorndycraft, 2004).

El impacto socioeconómico que estos fenómenos pueden llegar a ocasionar y la escasez de estudios en perspectiva histórica que aborden la relación entre la fusión nival y el desencadenamiento de movimientos en masa rápidos, especialmente en el ámbito de la Península Ibérica, justifican la necesidad de realizar trabajos como este, cuyos objetivos específicos son:

1. Cuantificar los movimientos en masa que se dieron y establecer sus localizaciones, dimensiones y tipologías, siempre que sea posible.

2. Computar los daños materiales y personales derivados de este episodio.

3. Determinar los factores desencadenantes - meteorológicos, antrópicos- prestando especial atención a la conexión existente entre el deshielo y los diferentes eventos generados.

\section{2 Área de estudio}

El Macizo Asturiano (Figura 1) constituye el sector occidental de la Cordillera Cantábrica, que se extiende hacia el Este hasta el País Vasco. Dicho macizo tiene como rasgo topográfico más notable la existencia de una amplia superficie que se encuentra por encima de los 1500 m s.n.m., cuyo origen se encuentra en el levantamiento que tuvo lugar como consecuencia de un extenso cabalgamiento de basamento durante la orogenia Alpina, que también consiguió reactivar antiguas estructuras hercinianas (Pulgar et al., 1999). Las principales cumbres del Macizo están conformadas por afloramientos masivos de calizas carboníferas, destacando el que constituyen los Picos de Europa, conjunto montañoso que representa el techo altitudinal de la Cordillera Cantábrica (Torrecerredo, $2648 \mathrm{~m}$ ).

La litología, sin embargo, es muy variada de oeste a este, con un predominio de materiales silíceos -esencialmente arenisca, pizarra y cuarcita- en la zona occidental, y una alternancia de rocas sedimentarias calcáreas y silíceas en el área central y oriental, hasta llegar al gran afloramiento carbonatado que representan los Picos de Europa. En líneas generales podemos afirmar que predominan las rocas sedimentarias y metamórficas, y que la mayor parte de los escarpes rocosos están compuestos de caliza, cuarcita y arenisca. 
Figura 1. Área de estudio y localización de movimientos en masa documentados durante los temporales de 1888, según su tipología

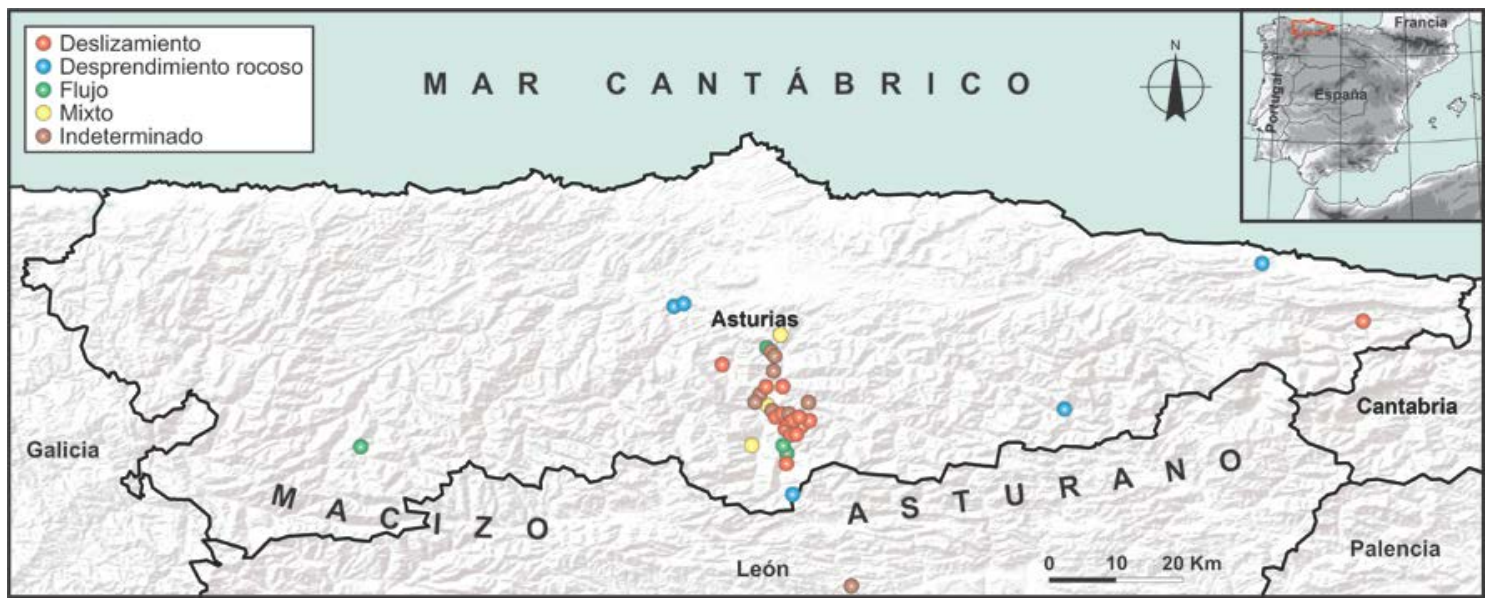

Fuente: elaboración propia a partir de trabajo de campo y fuentes históricas

El Macizo presenta una marcada disimetría topográfica norte-sur, con pendientes mucho más acusadas y abruptas en la vertiente norte. En sus sectores culminantes, por lo general, se superan los $2000 \mathrm{~m}$, existiendo también numerosos sectores de media montaña con altitudes comprendidas entre 1000 y 1500 m. Por tanto, se trata de un ámbito caracterizado, en líneas generales, por la existencia de grandes desniveles, valles muy encajados y laderas de notable pendiente. Este abrupto relieve ha favorecido el desarrollo de una red hidrográfica altamente fragmentada, caracterizada por las reducidas dimensiones de sus cuencas, la altitud de las cabeceras, la importante capacidad erosiva y el desarrollo de numerosos sistemas torrenciales -más de 7500(Fernández Iglesias et al., 2010). Además, más del 50 \% de la red hidrográfica está representada por áreas de cabecera en las que predominan los procesos de transporte en masa, destacando los ríos del Macizo por tener una importante carga de fondo (Santos y Menéndez, 2006).

La disimetría norte-sur se manifiesta también climáticamente, de modo que la vertiente norte del Macizo se caracteriza por sus suaves temperaturas -entre 10 y $14^{\circ} \mathrm{C}$ de media anual- y su alta humedad, presentando valores medios anuales de precipitación que oscilan entre 1400 y 1500 mm repartidos de forma regular a lo largo de todo el año (Fernández Iglesias et al., 2010), incluso superando los 2000 mm en áreas muy elevadas de exposición norte (Muñoz, 1982)-, mientras la sur tiene un clima de tipo transicional atlántico-mediterráneo, con temperaturas medias anuales inferiores a $10^{\circ} \mathrm{C}$, precipitaciones que sólo alcanzarán los $1000 \mathrm{~mm}$ en los puntos más elevados y de uno a dos meses de aridez estival.

La presencia humana en las áreas montañosas del Macizo ha estado relacionada tradicionalmente con el aprovechamiento ganadero, siendo continua la movilidad de grupos humanos entre las partes bajas y altas, así como entre ambas vertientes a través de los puertos de montaña, áreas preferentes para el transporte de reses, viajeros y mercancías. En las dos últimas décadas del siglo 
XIX las comunicaciones experimentaron un enorme impulso, merced a la construcción de numerosos tramos ferroviarios y carreteras principales. Con la inauguración de la Rampa de Pajares en el año 1884, que permitió unir la ciudad de Gijón con León -y a su vez con Madrid-, este puerto, contemplado ya en el plan jovellanista del siglo XVIII como vía preferente de comunicación con La Meseta, se convirtió en un punto vital para el desarrollo de la economía asturiana. Por tanto, a pesar de la dureza del entorno, en las áreas montañosas del Macizo se han desarrollado economías muy activas y son abundantes las infraestructuras, cuya construcción experimenta un gran impulso a partir de 1850. Las rigurosas condiciones climáticas que son propias de los espacios montañosos afectan tanto a estas infraestructuras como a los propios núcleos de población de las zonas más elevadas, que pueden verse afectados por los eventos derivados de las tempestades invernales.

\section{Metodología}

Para la realización de este estudio se ha combinado el análisis de archivos históricos de diversa tipología con el trabajo de campo, con el fin de reconstruir este episodio de movimientos en masa cubriendo aspectos relativos a las condiciones nivometeorológicas, los posibles agentes causales, las repercusiones socioeconómicas y ambientales de los eventos desencadenados, así como la identificación y localización de los mismos.

Las fuentes empleadas han sido: 1) La prensa local de la época, los diarios El Carbayón, El Comercio (Figura 2) y El Diario de León, así como el semanario El Oriente de Asturias y el periódico trimensual La Tía Cacica entre el 20 de enero y el 30 de mayo de 1888. Se han revisado 162 ejemplares recurriendo a los archivos en soporte microfilmado, conservados en el fondo de la Biblioteca Central de Asturias, y 62 en la hemeroteca de la Biblioteca Nacional de España; 2) Los libros de difuntos de los archivos parroquiales correspondientes a 19 parroquias distribuidas en los concejos afectados por el episodio -Cangas del Narcea, Oviedo, Mieres, Lena, Aller, Caso y Peñamellera Alta-, con el objetivo de corregir posibles omisiones de la prensa en relación a la mortalidad directa ocasionada por el episodio; 3) Los datos diarios relativos a temperatura y precipitación para los meses de enero, febrero, marzo y abril de 1888, contenidos en el archivo meteorológico de la antigua estación de la Universidad de Oviedo.

También se ha realizado trabajo de campo para complementar la reconstrucción de los hechos a través de la prensa, mediante la inspección del lugar donde sucedieron, basándonos en testimonios orales y evidencias geomorfológicas. Esta parte del trabajo ha sido fundamental para conocer en algunos casos las tipologías de los movimientos, el punto aproximado de desencadenamiento y el recorrido que hicieron los materiales desplazados. El trabajo de campo ha permitido también corregir, cuando las hubiera, informaciones erróneas aparecidas en la prensa de la época. 
Figura 2. A modo de ejemplo, dos noticias publicadas por los diarios El Comercio, 26 de febrero (a) y El Carbayón, 9 de marzo (b), durante los temporales de nieve de 1888

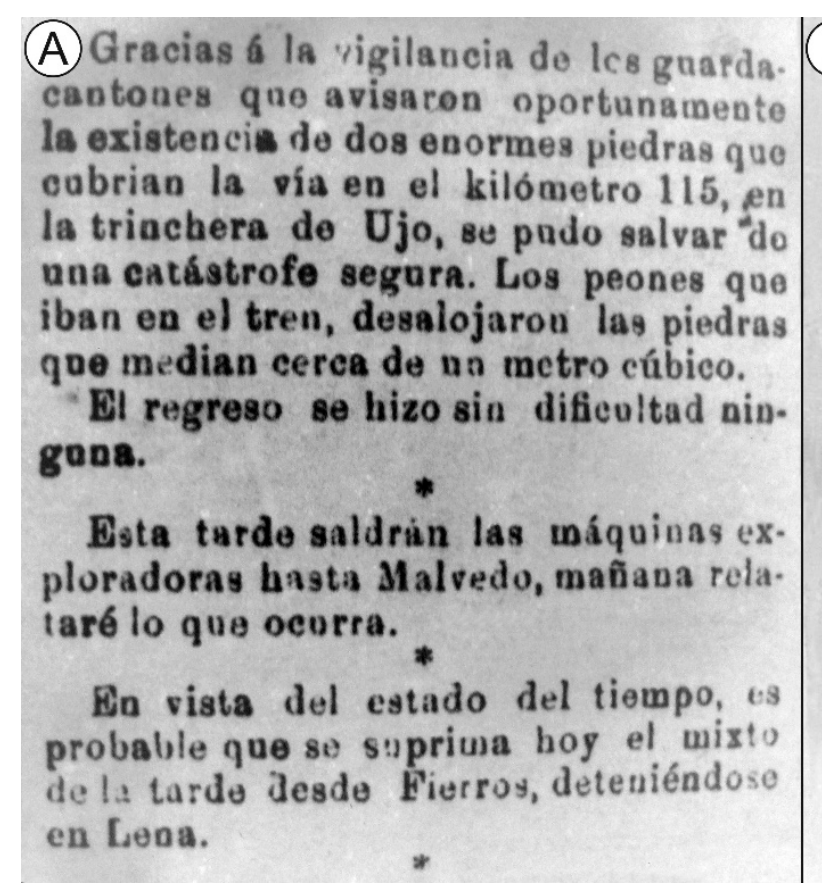

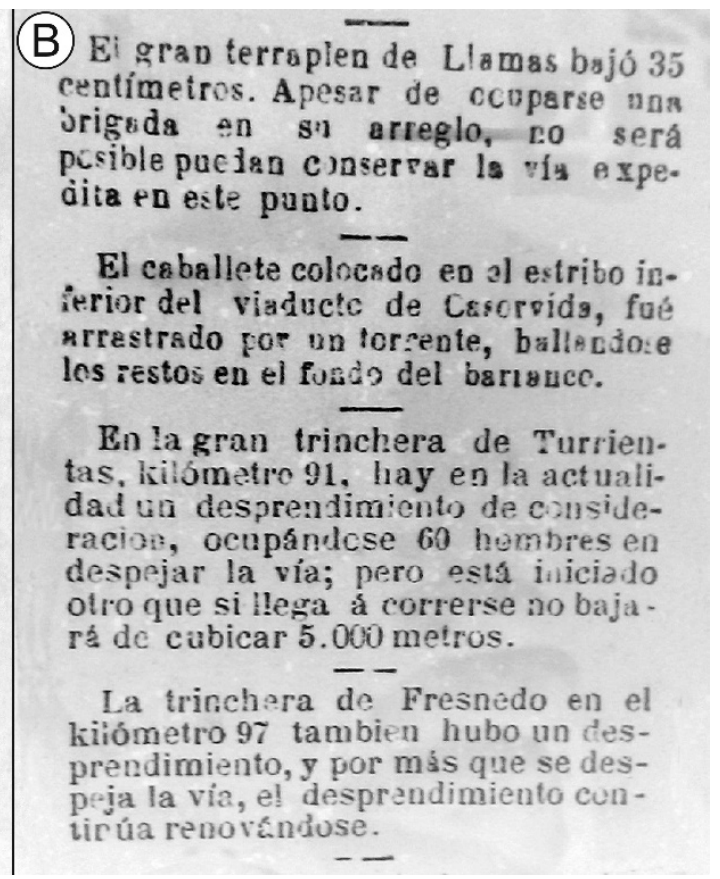

Fuente: elaboración propia a partir de fuentes históricas

\section{Resultados}

\subsection{Número de sucesos y localización}

Se han documentado 36 sucesos (Tabla 1), 21 de los cuales se produjeron en el concejo de Lena. A este concejo le siguen Mieres (5) y Oviedo (4). El resto de movimientos documentados se produjeron en los concejos de Cangas del Narcea, Aller, Caso, Riosa, Peñamellera Alta, Llanes y La Robla (León) (Figura 3). También se documentaron desprendimientos recurrentes, por ejemplo, el día 7 de marzo apunta el diario El Carbayón: «El tren mixło llegó anoche con hora y media de retraso, a causa de un desprendimiento ocurrido en el km 115 entre Lena y Ujo», sin embargo el 26 de febrero, durante la primera tregua, en el mismo periódico ya se había señalado: «hemos estado expuestos a estrellarnos contra unas rocas que se desprendieron de la montaña en el km 115, cerca de Ujo». En algunos casos la liberación de materiales fue continua, por ejemplo en el kilómetro 97 de la vía León-Gijón, en las cercanías del pueblo de Fresnedo, «...también hubo un desprendimiento, y por más que se despeja la vía, el desprendimiento continúa renovándose» (E) Carbayón, 9 de marzo de 1888), algo similar ocurrirá en los kilómetros 83 y 85, donde se darán movimientos de ladera de forma reiterada a lo largo de todo el episodio de nevadas. De hecho, al menos tres de los 36 movimientos se habían producido ya en años anteriores, repitiéndose durante el episodio de 1888. 
Figura 3. Localización de los concejos asturianos en los que se han documentado movimientos en masa durante el episodio de 1888

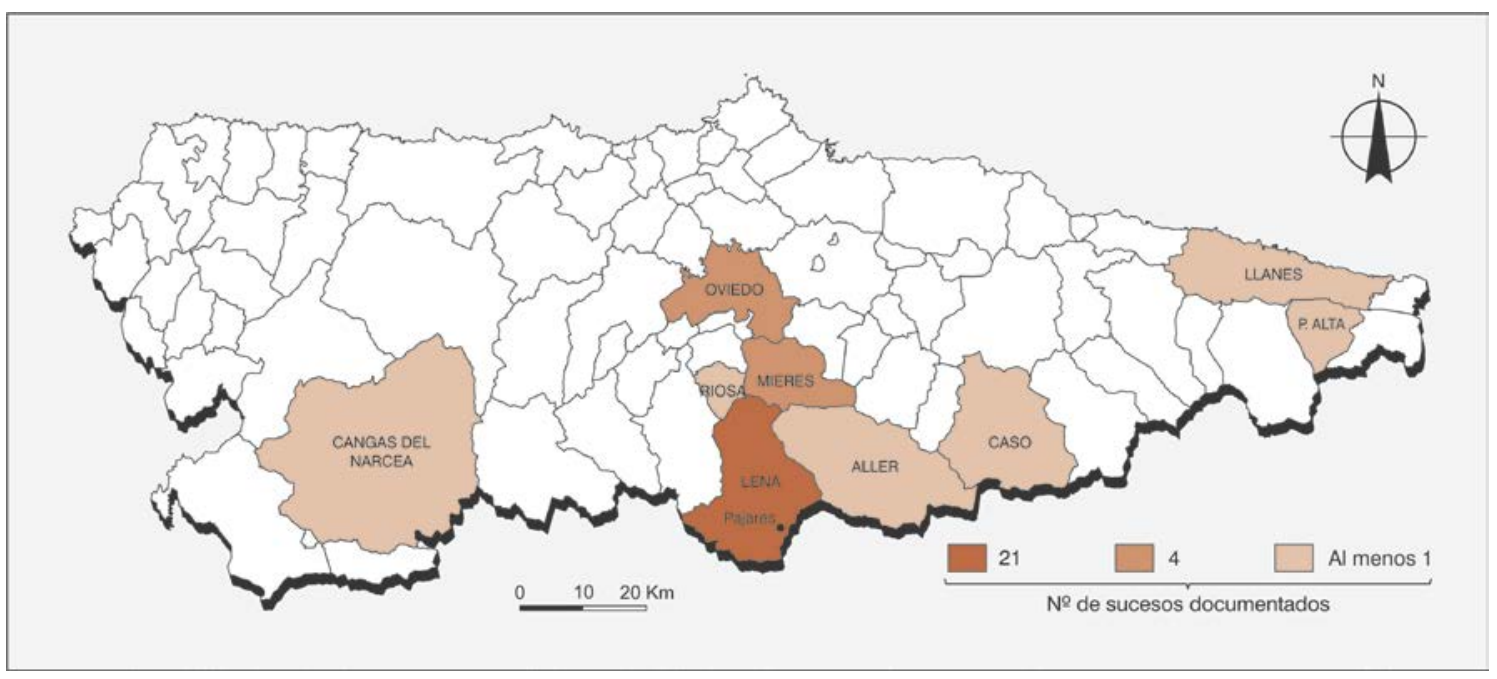

Fuente: elaboración propia a partir de trabajo de campo y fuentes históricas

\subsection{Condiciones nivometeorológicas}

El episodio consistió en cuatro temporales de nieve que se sucedieron entre el 14-20 de febrero, 24-29 de febrero, 14-22 de marzo y 3-8 de abril de 1888. Aunque los movimientos en masa se darán durante todo el episodio de nevadas, su número y frecuencia aumentaron durante las treguas, anunciándose el mayor número durante el segundo receso en el temporal, a partir de la primera semana de marzo. Concretamente entre el 8 y el 14 de marzo se notificarán 10 inestabilidades, coincidiendo con un incremento de las temperaturas $y$, por tanto, con un aumento de la fusión de la nieve, que durante los dos primeros temporales había alcanzado espesores de hasta 9 m en el Puerto de Pajares (1000 m s.n.m.), 5 m en el de Tarna (1492 m) y hasta 6 m en las inmediaciones del pueblo de Bulnes $(650 \mathrm{~m})$. La relación entre la evolución de las temperaturas y las precipitaciones, y la de los eventos relacionados con movimientos en masa, puede ser fácilmente apreciada a través de los gráficos contenidos en las Figuras 4 y 5 -que relacionan precipitaciones de nieve o lluvia diarias en Oviedo con temperaturas máximas, mínimas y media, y a su vez con el número de movimientos en masa que se produjeron en todo el territorio estudiadoEn la primera de ellas se observa que, tras un periodo de intensas precipitaciones de nieve que en Oviedo alcanzaron los $35 \mathrm{I} / \mathrm{m}^{2}$ el 20 de febrero, comienzan a darse los primeros movimientos en el resto del Macizo. Si bien el momento de mayor incidencia coincidirá con la subida de las temperaturas medias, que pasan de rondar los $0^{\circ} \mathrm{C}$ el día 29 de febrero - día en que finaliza la segunda nevada-, a alcanzar $14^{\circ} \mathrm{C}$ el 13 de marzo (Figura 5). Esa escalada de las temperaturas permitirá la fusión de la nieve depositada y el inicio del deshielo durante la segunda tregua. Con anterioridad a esas fechas, los desprendimientos sólo fueron notificados de forma puntual y se limitaron al trazado de la vía férrea. 
Asimismo, debemos señalar que, tal como se observa en la Figura 4, entre los días 10 y 14 de marzo se registraron en Oviedo precipitaciones de lluvia de hasta $12,9 \mathrm{l} / \mathrm{m}^{2}$. En el resto del Macizo, a partir del día 14 se tienen noticias del comienzo de un nuevo temporal de nieve, que se intensifica los días posteriores prolongándose hasta el 24 de marzo. Esta tercera nevada genera nuevos espesores que en Puente de los Fierros (500 m s.n.m.) alcanzan 1,5 m, y hasta 2,5 m en Pajares $(1000 \mathrm{~m})$. Por tanto, esas precipitaciones que en Oviedo fueron registradas como Iluvia entre el 14 y el 17, así como entre el 21 y 24 de marzo, en las zonas altas del Macizo se manifestaron como precipitaciones de nieve que se dieron de forma ininterrumpida entre el 14 y el 24 de dicho mes.

Figura 4. Precipitaciones de nieve o lluvia diarias en Oviedo y número de movimientos en masa en todo el territorio estudiado

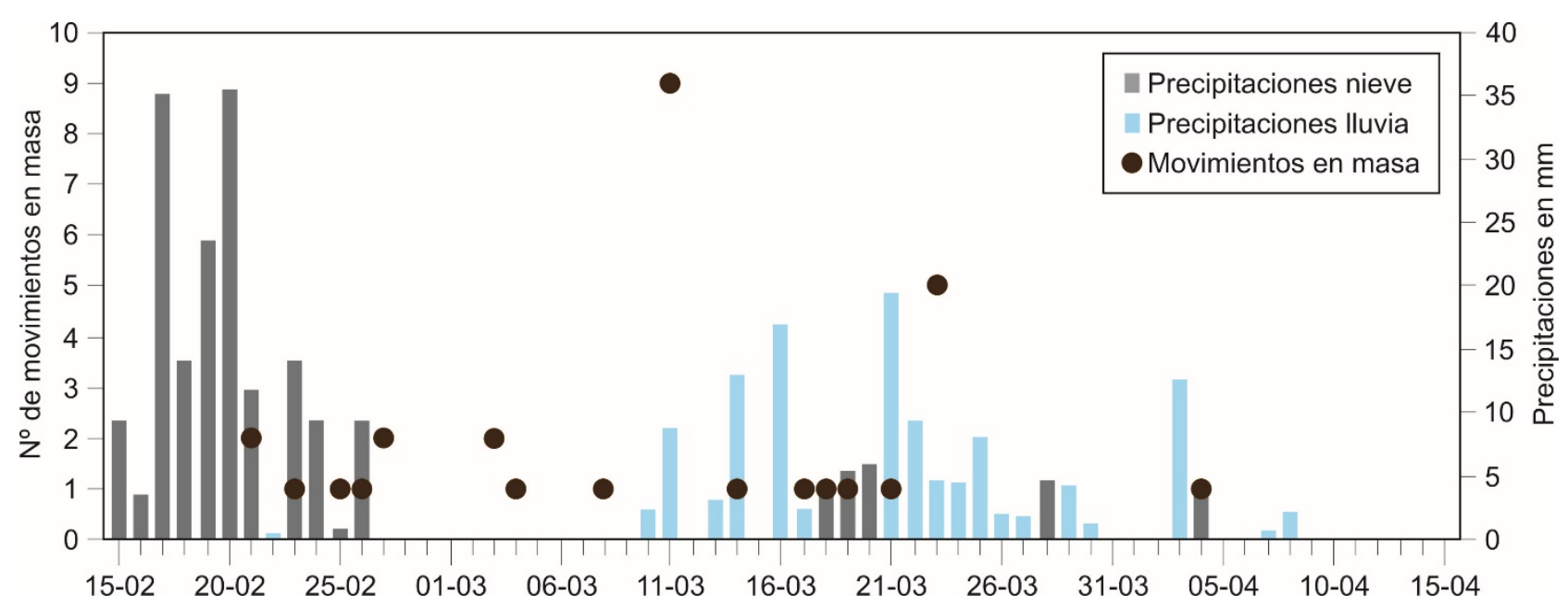

Fuente: elaboración propia a partir de los datos del antiguo observatorio meteorológico de la Universidad de Oviedo 
Tabla 1. Localización, fecha, tipología, dimensiones, agentes causales implicados

y principales consecuencias de los movimientos en masa desencadenados

\begin{tabular}{|c|c|c|c|c|c|c|c|}
\hline FECHA & CONCEJO & LUGAR & TIPO & $\begin{array}{c}\text { DIMENSIONES } \\
\text { valoración cuantitativa/cualitativa }\end{array}$ & TIPO DE SUSTRATO & $\begin{array}{l}\text { CONDICIONANTES } \\
\text { origen antrópico }\end{array}$ & CONSECUENCIAS \\
\hline $21 / 02$ & MIERES & Ablaña & --- & --- & Aluviones (Cuaternario) & $\begin{array}{c}\text { Modificación } \\
\text { Topografía (M.T.) }\end{array}$ & Obstrucción de la vía \\
\hline $21 / 02$ & LENA & Pola de Lena & --- & "Sin importancia" & Pizarra, caliza y arenisca (Carbonífero) (P.C.A.) & M.T. & Obstrucción de la vía \\
\hline $23 / 02$ & LENA & Pola de Lena & Deslizamiento & --- & P.C.A. & --- & --- \\
\hline $25 / 02$ & LLANES & $\begin{array}{l}\text { Posada de Llanes, } \\
\text { carretera a Nueva }\end{array}$ & $\begin{array}{l}\text { Desprendimiento } \\
\text { rocas (D.R.) }\end{array}$ & "Grandes dimensiones" & $\begin{array}{c}\text { Conglomerado, cuarcita, arenisca y limolita } \\
\text { (Ordovícico) }\end{array}$ & --- & $\begin{array}{c}\text { Intercepta por varios días la } \\
\text { carretera }\end{array}$ \\
\hline $26 / 02$ & MIERES & Estación de Ujo & --- & --- & Aluviones (Cuaternario) & M.T. & Obstrucción de la vía \\
\hline $27 / 02$ & OVIEDO & Olloniego & Mixto & $3.000 \mathrm{~m}^{3}$ & $\begin{array}{l}\text { Areniscas, pizarras, calizas y dolomías } \\
\text { (Devónico) }\end{array}$ & M.T. & Obstrucción de la vía \\
\hline $27 / 02$ & LA ROBLA & Km 11 León-Gijón & --- & --- & Aluviones (Cuaternario) & M.T. & Obstrucción de la vía \\
\hline $03 / 03$ & OVIEDO & Trubia, la Boza & D.R & Roca de 4-5 metros & Calizas y pizarras (Devónico) & M.T. & Obstrucción de la vía \\
\hline $04 / 03$ & LENA & Km 91 León-Gijón & Deslizamiento & $500 \mathrm{~m}^{3}$ & P.C.A. & M.T. & Obstrucción de la vía \\
\hline $08 / 03$ & MIERES & Estación de Mieres & --- & --- & Aluviones (Cuaternario) & M.T. & Obstrucción de la vía \\
\hline $09 / 03$ & LENA & Puente los Fierros & Flujo & --- & P.C.A. & --- & Daña severamente dos casas \\
\hline $11 / 03$ & LENA & Linares & Deslizamiento & La vía desciende $1 \mathrm{~m}$ & P.C.A. & M.T. & Obstrucción de la vía \\
\hline $11 / 03$ & LENA & Km 83 León-Gijón & Deslizamiento & "De mucha importancia" & P.C.A. & M.T. & Obstrucción de la vía \\
\hline $11 / 03$ & LENA & Km 84 León-Gijón & Deslizamiento & "Gran desprendimiento" & P.C.A. & M.T. & Obstrucción de la vía \\
\hline $11 / 03$ & LENA & Km 85 León-Gijón & Mixto & --- & P.C.A. & M.T. & Obstrucción de la vía \\
\hline $11 / 03$ & LENA & Km 91 León-Gijón & Deslizamiento & "Grandes dimensiones" & P.C.A. & M.T. & Obstrucción de la vía \\
\hline $11 / 03$ & MIERES & Km 122 León-Gijón & Flujo & --- & Aluviones (Cuaternario) & M.T. & $\begin{array}{c}\text { Obstrucción de la vía y daños } \\
\text { en huertas aledañas }\end{array}$ \\
\hline $11 / 03$ & LENA & Km 81 León-Gijón & Deslizamiento & La vía desciende $40 \mathrm{~cm}$ & P.C.A. & M.T. & Obstrucción de la vía \\
\hline $11 / 03$ & LENA & Terraplén Llamas & Deslizamiento & La vía desciende $35 \mathrm{~cm}$ & P.C.A. & M.T. & Obstrucción de la vía \\
\hline $11 / 03$ & C.NARCEA & Folgueraxú & Deslizam./Flujo & Flujo $>1,2 \mathrm{Km}$ de longitud & Areniscas y pizarras (Precámbrico) & --- & Destruye dos edificaciones \\
\hline $14 / 03$ & CASO & La Foz & D.R. & "Enorme" & Caliza de montaña (Carbonífero) & --- & Intercepta la carretera \\
\hline $17 / 03$ & LENA & Km 83 León-Gijón & Deslizamiento & --- & P.C.A. & M.T. & Obstrucción de la vía \\
\hline $18 / 03$ & RIOSA & Riosa & Deslizamiento & --- & P.C.A. & --- & Destruye varias edificaciones \\
\hline $20 / 03$ & LENA & La Coaña & --- & --- & P.C.A. & --- & Intercepta la carretera \\
\hline $20 / 03$ & LENA & Puente los Fierros & Flujo & "Gran torrente" & P.C.A. & Escombrera & Arrasa carretera y una fuente \\
\hline $21 / 03$ & LENA & Km 100 León-Gijón & Mixto & $40 \mathrm{~m}^{3}$ & P.C.A. & M.T. & Obstrucción de la vía \\
\hline $23 / 03$ & LENA & Km 101 León-Gijón & --- & "Pequeño tamaño" & P.C.A. & M.T. & Obstrucción de la vía \\
\hline $23 / 03$ & MIERES & La Muela & Deslizamiento & "Gran corrimiento" & P.C.A. & --- & Desalojo parte del vecindario \\
\hline $23 / 03$ & ALLER & La Rumia & --- & --- & P.C.A. & --- & --- \\
\hline $23 / 03$ & LENA & Km 83 León-Gijón & Deslizamiento & $170 \mathrm{~m}^{3}$ & P.C.A. & M.T. & Obstrucción de la vía \\
\hline $24 / 03$ & LENA & Km 91 León-Gijón & Deslizamiento & $5.000 \mathrm{~m}^{3}$ & P.C.A. & M.T. & Obstrucción de la vía \\
\hline $23 / 03$ & LENA & Sotiello & Mixto & --- & P.C.A. & --- & Intercepta la carretera \\
\hline $04 / 04$ & $\begin{array}{l}\text { PENAM. } \\
\text { ALTA }\end{array}$ & El Pontón & Deslizamiento & $\begin{array}{l}\text { La carretera se hunde en un tramo } \\
\text { de } 12 \mathrm{~m}\end{array}$ & $\begin{array}{c}\text { Calizas de grano fino y calizas margosas } \\
\text { (Formación Puentellés, Carbonífero) }\end{array}$ & --- & $\begin{array}{l}\text { El pueblo de Ruenes queda } \\
\text { aislado durante varios días }\end{array}$ \\
\hline $16 / 04$ & LENA & Túnel Congostinas & Deslizamiento & $400 \mathrm{~m}^{3}$ & P.C.A. & M.T. & Obstrucción de la vía \\
\hline $16 / 04$ & OVIEDO & Trubia & D.R. & --- & Calizas y pizarras (Devónico) & M.T. & Obstrucción de la vía \\
\hline $25 / 04$ & LENA & Pajares & D.R. & --- & P.C.A. & --- & Muerte de un campesino \\
\hline
\end{tabular}

Fuente: elaboración propia a partir de trabajo de campo, fuentes históricas y análisis de cartografía geológica 


\subsection{Impacto a mbiental y socioeconómico}

La mayor parte de los movimientos documentados se dieron en el trayecto ferroviario entre Oviedo y León (Tabla 1), por lo que el principal impacto generado se tradujo en numerosas obstrucciones de la vía férrea - con los consiguientes retrasos en la entrega del correo, la falta de géneros y mercancías en tiendas e instalaciones fabriles, la imposibilidad de exportar mercancías, etc.-. En los diarios asturianos aparecieron anotaciones como las que siguen: «En la gran trinchera de Turrinetos, kilómetro 91, hay en la actualidad un desprendimiento de consideración, ocupándose 60 hombres en despejar la vía» (Figura 2); «En el kilómetro 128 entre las estaciones de Olloniego y Las Segadas hubo un fuerte desprendimiento de unos 3000 metros cúbicos de tierra que impedirá el paso durante 4 días, teniendo que hacer los trenes trasbordo en dicho punto» (El Comercio, 9 de marzo de 1888), «...se interceptó la vía en el kilómetro 100, entre Fierros y Campomanes, por desprendimientos de tierras y piedra de unos 40 metros cúbicos. Con tal motivo el tren mixto llegó a Fierros con treinta minutos de retraso» (El Carbayón, 10 de marzo de 1888).

Figura 5. Temperaturas máximas, mínimas y medias en Oviedo y número de movimientos en masa en todo el territorio estudiado

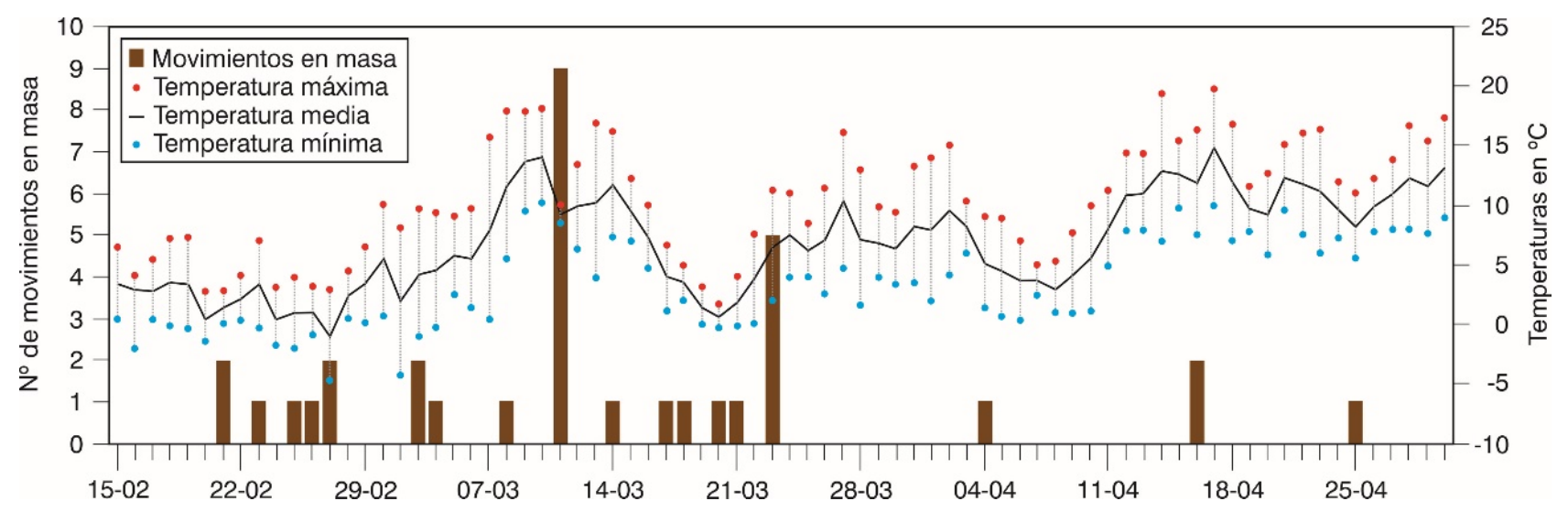

Fuente: elaboración propia a partir de los datos

del antiguo observatorio meteorológico de la Universidad de Oviedo

Si dejamos a un lado las principales vías de comunicación, los eventos sólo serán anunciados cuando produzcan importantes daños materiales o personales, o bien cuando sean de grandes dimensiones. Es el caso de los dos movimientos sucedidos en La Muela (Lena), considerados como tal amenaza por parte de los vecinos, que éstos se vieron obligados a abandonar sus casas, pues tras el derribo de algunas pequeñas construcciones y decenas de árboles, temían que el pueblo entero quedase destruido: «En la muela, pueblo sobre la carretera, hubo dos desgajes de gran consideración, y han tenido que ser desalojadas las casas tanto por esto, como por el desprendimiento de infinidad de árboles que se teme destruyan el pueblo» (El Comercio, 10 de marzo de 1888). O el producido en el pueblo de La Foz (Caso) el 14 de marzo, cuando en pleno deshielo se produjo el desprendimiento de una «inmensa mole de piedra» en una de las paredes 
rocosas que rodean el pueblo. A ese primer desprendimiento sucedieron otros de similar consideración, que bloquearon el camino y pusieron en riesgo la vida de aquellos que entraban o salían por él, lo que obligó a la autoridad local a tomar medidas con el fin de evitar daños mayores.

Estos sucesos no sólo fueron peligrosos para los habitantes de algunos pueblos sino que también fueron causantes de prolongadas situaciones de aislamiento. En cuanto al ferrocarril, entre el 21 de febrero y el 25 de abril se notificaron hasta 22 situaciones de retrasos en las comunicaciones, derivados de movimientos en masa que afectaron a la vía férrea, con depósitos que tardaron hasta 5 días en ser despejados. Otras seis situaciones de incomunicación afectaron a carreteras y caminos principales, prolongándose en todos los casos durante días, debido a la falta de medios para despejar este tipo de vías. Un buen ejemplo se dio en Trescares (Peñamellera Alta), donde el único camino que comunicaba el pueblo con otros como Oceño y Ruenes, desapareció en un tramo de 12 metros a causa de un deslizamiento producido a principios de abril, que un suscriptor de la zona describe de la siguiente manera: «Este pueblo se halla incomunicado con el inmediato de Ruenes a causa de un espantoso hundimiento de terreno que sumió media ería llamada del Pandio por el sitio conocido por El Pontón, produciendo una sima tan asombrosa que infunde terror» (El Carbayón, 11 de abril de 1888). Algo parecido ocurrió entre Sotiello y Tuiza, debido a un movimiento de ladera que hizo «...intransitable el camino entre los dos pueblos» (El Comercio, 23 de marzo de 1888), o entre Posada y Nueva de Llanes, donde se produjo «...un desprendimiento que intercepta prácticamente la vía pública» (El Carbayón, 25 de febrero de 1888).

Pero, si bien los desprendimientos afectaron fundamentalmente a las comunicaciones al obstruir las vías de conexión, también ocasionaron graves daños en las propiedades, incluidas algunas edificaciones (al menos 6). Algunos casos ya se han citado, pero un ejemplo notorio lo constituye el producido en Puente los Fierros durante la noche del 6 de marzo, dando lugar al hundimiento de la casa-oficina del ferrocarril, en la que habitaban dos familias de empleados de la vía férrea. Para evacuar el agua y el lodo que la inundaban fue preciso romper la pared maestra que daba a un comercio anexo que quedó, de este modo, severamente dañado perdiendo «todas las harinas y demás géneros». Por temor a nuevos sucesos de este tipo otras personas desalojaron sus casas en dicha localidad: «...también las familias de los dos jefes de vía y obras y del escribiente han abandonado las suyas, a causa de la enorme cantidad de agua y los grandes corrimientos de tierras de la ladera vecina» (El Comercio, 10 de marzo de 1888).

En cuanto a las fincas rústicas, un gran número de ellas quedaron en mal estado, algo que sólo pudo comprobarse tras la retirada definitiva de la cubierta nival. A finales de marzo la prensa comienza a hacerse eco de los daños ocasionados en ellas, bien debido a la erosión y pérdida de suelos - por ejemplo, desde el concejo de Aller, dice un suscriptor del periódico El Carbayón: «En las pendientes el deshielo ha arrastrado la tierra vegetal dejando al descubierto piedra y pizarra, los 
prados están surcados de grietas enormes» (El Carbayón, 23 de mayo de 1888) - o bien por estar tapizadas las tierras de labor por los materiales movilizados desde las laderas, quedando muchas fincas «cubiertas de pedregal desprendido de las alturas por las nevadas» (El Oriente de Asturias, 26 de mayo de 1888), lo que ese año dificultó el arado haciendo imposible, en muchos casos, la siembra. También los cursos de agua se vieron perjudicados durante el deshielo, siendo frecuentes los testimonios de suscriptores que, desde diferentes puntos del Macizo -incluida su vertiente sur hacia León-, describían la enorme carga que arrastraban los ríos y arroyos en aquellos días «tornándose el líquido elemento que riega y nutre los campos y vegas, de ordinario cristalino, en oscuro y ennegrecido torrente (....) alterando incluso el funcionamiento de algunos manantiales» (El Carbayón, 20 de marzo de 1888).

Por último, como resultado de este episodio de movimientos en masa sólo se ha documentado un fallecimiento -también producido en Lena-, el de José Fernández, de 26 años, que murió al ser alcanzado por un desprendimiento rocoso mientras trabajaba en unas tierras cercanas a la localidad de Pajares, a mediados del mes de abril de 1888.

\subsection{Tipologías, condicionantes y desencadenantes}

Veintiocho de los 36 sucesos han podido ser clasificados gracias a las descripciones ofrecidas por la prensa de 1888, si bien en este sentido han sido fundamentales el trabajo de campo y los testimonios que nos llegan a través de los habitantes actuales de las zonas afectadas; 15 de ellos se correspondieron con deslizamientos, cinco con desprendimientos de rocas, cuatro fueron flujos y otros cuatro fueron movimientos de tipología mixta - desprendimientos rocosos con abundante cantidad de tierra-.

Alguno de los movimientos producidos fue capaz de movilizar gran cantidad de material. Este fue el caso del que se produjo el 11 de marzo en el concejo de Cangas del Narcea (Figuras 6 y 7), un suceso de gran magnitud, aunque sin consecuencias desde el punto de vista personal:

(...) una gran avalancha de nieve y tierra que se desprendió en las inmediaciones de Folguerajú, bajando por una gran pendiente con dirección a Murias, destrozando la casa del labrador José Fuertes Antón, llevándole las portonas del corral, dos carros, el almacén de las patatas y ocho gallinas que estaban en el portal, un carro quedó colgado en un peral debajo de la corralada, una rueda del otro fue a parar a Pontarás a un kilómetro de distancia en la misma pendiente, la otra rueda, la caja del carro y las portonas envueltas entre la nieve se precipitaron al río, dando tan fuerte choque contra él que a pesar de estar crecido le hizo mudar de cauce pasando ahora por los prados que están frente al citado Pontarás, sin que hasta la fecha haya sido posible hacerlo volver a la madre, causando incalculables perjuicios. La caja del carro y las portonas las vieron pasar por Bimeda, a más de 8 kilómetros de distancia. Gracias a Dios no hubo 
desgracias personales, las pérdidas del labrador José Fuertes Antón se calculan en 6000 reales (El Carbayón, 14 de marzo de 1888).

Las entrevistas realizadas en la zona revelan que el contenido de la avalancha era fundamentalmente tierra. En el momento en que se desencadenó, un vecino realizaba trabajos en una finca del pueblo de Folgueraxú -situado en la misma ladera pero unos 150 m por encima del de Murias- para tratar de que circulara el agua que, obstruida por la nieve y la tierra, inundaba su propiedad. El material, que según los testimonios se encauzó por el valle que desciende hacia Pontarás acompañado de gran cantidad de agua, fluía «como un río de lodo» y arrasó todo cuanto halló a su paso, incluidos árboles de gran tamaño. Finalmente alcanzó el río Naviego, el cual obstruyó por completo durante días, causando indirectamente inundaciones en las fincas vecinas al río, pertenecientes al pueblo de Pontarás. El trabajo de campo ha permitido comprobar que, en la ladera en la que se desencadenó el movimiento, el sustrato es pizarroso y, por lo general, sobre él no se desarrolla un suelo -o una acumulación sedimentaria- que supere los 0,5 m de espesor. Sin embargo, en el lugar que los vecinos señalan como punto aproximado de arranque, se distingue hoy una pequeña cabecera torrencial y, en ella, una zona cóncava abierta en un claro rodeado de bosque. En este punto la formación superficial gana potencia -hasta 1,5 m-, y es mayoritariamente arcillosa (Figuras 6 y 7 ).

Figura 6. Trayectoria seguida por el movimiento en masa de Folgueraxú desde su desencadenamiento hasta su deposición a nivel del río naviego, pasando por los pueblos de Murias de Pontarás y Pontarás

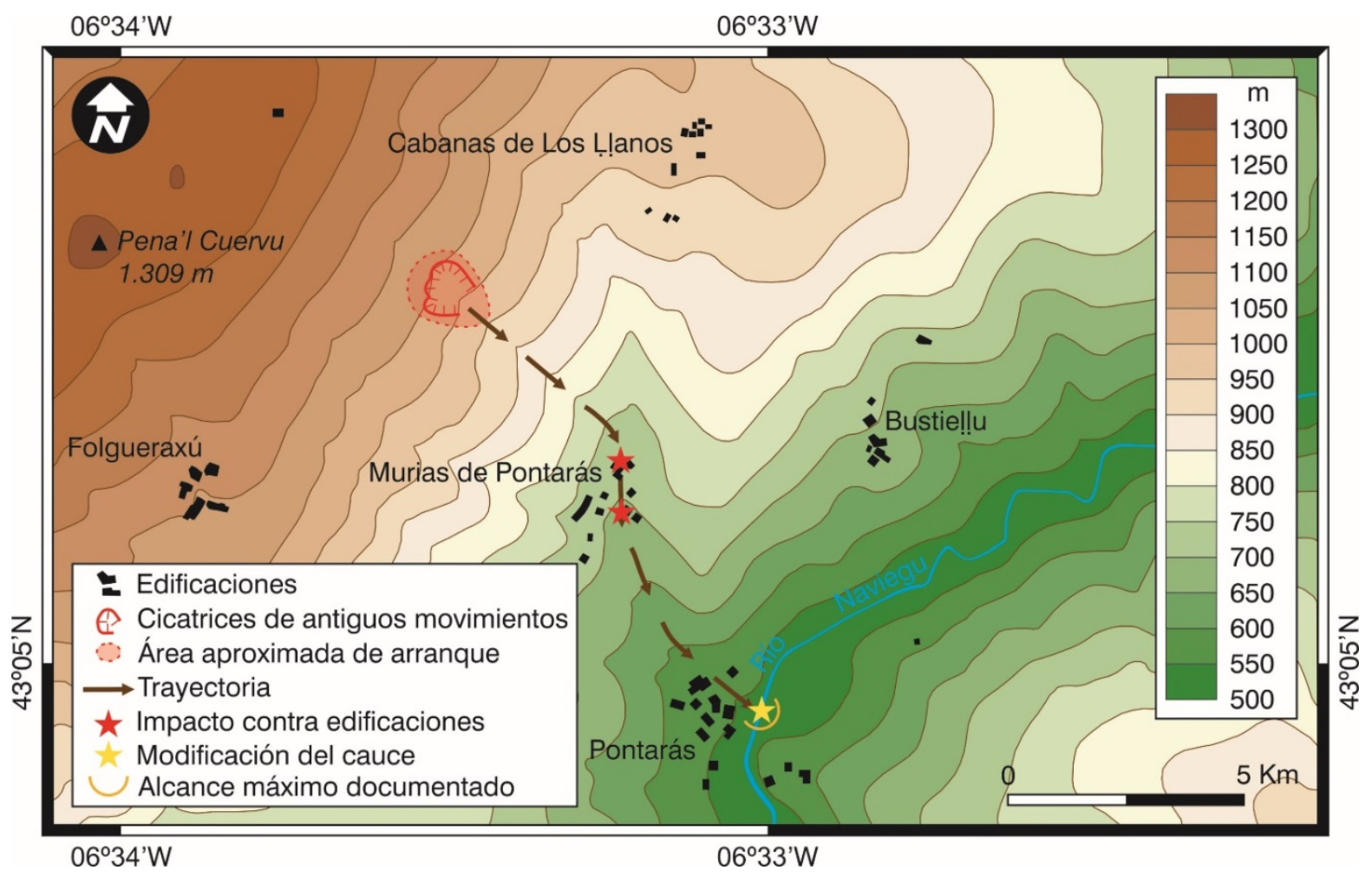

Fuente: elaboración propia a partir del trabajo de campo realizado 
Por otro lado, numerosas estructuras de origen antrópico estuvieron involucradas en eventos de este tipo. Siete terraplenes se vieron afectados por movimientos en masa, desmoronándose parte de los mismos o bien dándose descensos de hasta $1 \mathrm{~m}$ en sus cotas. En otros dos casos fueron escombreras: por ejemplo en Puente de los Fierros durante el deshielo que siguió a la segunda nevada, el agua del arroyo Orria, enormemente crecido, arrastró una escombrera del tiempo de la construcción del ferrocarril, generando un flujo de barro y escombros que arrastró la fuente del pueblo y la parte inferior de la carretera, para precipitarse después en las aguas del río Pajares «formando un verdadero torrente que intercepta el camino, solo abordable por medio de una tabla colocada a modo de puente sobre dos piedras» (El Carbayón, 19 de marzo de 1888) y amenazando incluso algunas edificaciones.

\section{Discusión}

\subsection{La fusión nival como agente causal}

Si bien varios factores pudieron actuar como condicionantes en el desarrollo del episodio de movimientos en masa de 1888, varios indicios apuntan a la fusión nival como desencadenante principal del mismo. Los factores causales que dan lugar a un movimiento de ladera se dividen en condicionantes -factores pre-existentes que originan una inestabilidad, siendo los más comunes de origen geológico, geomorfológico, climático y antrópico- y desencadenantes, procesos que suponen un estímulo inmediato para el desencadenamiento (Popescu, 1996). Las condiciones climáticas, la litología del sustrato, la presencia de una formación superficial sobre ella y la topografía -especialmente la pendiente- son los factores condicionantes. Las precipitaciones de Iluvia, los aportes del deshielo y las modificaciones locales antrópicas -operando sobre la cubierta vegetal o la propia topografía- son los principales factores desencadenantes. Durante el episodio de 1888 los movimientos en masa se dieron en mayor medida durante las treguas, especialmente tras la segunda nevada -entre el 29 de febrero y el 14 de marzo-, cuando un receso lo suficientemente prolongado en las precipitaciones, asociado a un aumento considerable de las temperaturas, permitió el inicio de la fusión masiva de la cubierta nival. En este sentido, la sucesión de episodios de precipitación intensa de nieve y subidas súbitas de la temperatura que observamos en las Figuras 5 y 6, parece encontrarse en el origen de las inestabilidades. En las zonas templadas húmedas, esta alternancia se encuentra generalmente en el origen de procesos de fusión rápida, capaces de dar lugar a eventos en los que se concentran numerosos movimientos en masa rápidos (Chleborad, 1997; Decaulne et al., 2005; Naudet et al., 2008; Rulli et al., 2013). 
Figura 7. Esquema que representa el lugar de desencadenamiento y la riega por la que se encauzó el movimiento en masa de Folgueraxú

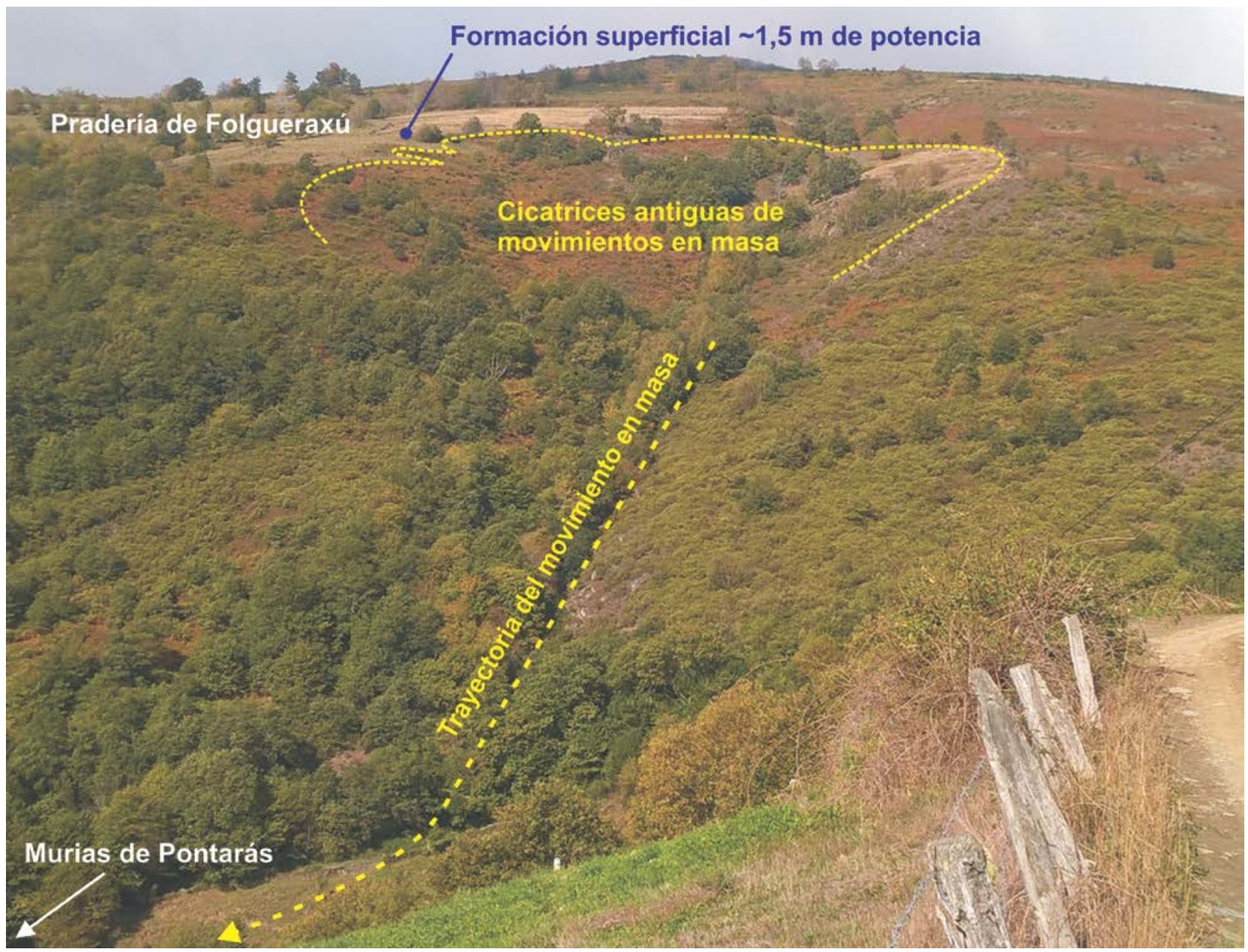

Fuente: elaboración propia a partir del trabajo de campo realizado.

Es necesario aclarar que, sin embargo, los días 10 y 11 de marzo -momento álgido en el desencadenamiento de inestabilidades - en el observatorio de Oviedo se registraron algunas precipitaciones de lluvia -que apenas superaron los $8 \mathrm{I} / \mathrm{m}^{2}$ el día 11-. ¿Pudo ser este y no el deshielo el desencadenante? Lo cierto es que la relación con las lluvias no parece relevante, en comparación con la que se establece de forma directa y clara con el incremento de las temperaturas y la consiguiente intensificación de los procesos de fusión nival (Figura 5). Existen estudios previos que demuestran que, los aportes acuosos derivados de la fusión nival, por si mismos y sin la existencia de precipitaciones de lluvia, son capaces de desencadenar grandes deslizamientos (Raetzo et al., 2002; Gokceoglu et al., 2005), flujos (Saemundsson et al., 2003; Decaulne et al., 2005), coladas de barro (Morton y Campbell, 1974) y desprendimientos de rocas (Glancy y Bell, 2000; Raetzo et al., 2002). Si bien, de todos los anteriormente mencionados, parece que los más comúnmente desencadenados por la fusión nival son los deslizamientos superficiales y los flujos (Schuster y Wieczorek, 2002) tal como sucedió en el episodio de 1888 en el que dichos movimientos conforman dos terceras partes de las tipologías identificadas. No 
debemos menospreciar, sin embargo, la posible influencia de las precipitaciones de lluvia a la hora de intensificar la fusión, siendo los episodios de lluvia sobre nieve capaces de causar una fusión masiva de la cubierta nival responsable de originar movimientos en masa rápidos (Horton, 1938; Harr, 1981; DeGraff et al., 1984; Wieczorek, 1996; Schuster y Wieczorek, 2002).

El aumento de la presión intersticial por la saturación del suelo, debido a los aportes de la fusión nival, parece haber sido el agente causal principal del episodio de movimientos en masa que se extendió desde el 21 de febrero hasta el 16 de abril de 1888, en el que los deslizamientos fueron la tipología más común. En el caso de los desprendimientos de rocas, la penetración del agua de fusión en las grietas de las masas rocosas es capaz de generar elevadas presiones hidrostáticas que serán la causa última del desprendimiento (Schuster y Wieczorek, 2002). La infiltración de aguas de fusión supone un desencadenante común de movimientos en masa rápidos en espacios montañosos (Varnes, 1978; Wieczorek, 1996; Raetzo et al., 2002; Naudet et al., 2008), existiendo además diferencias en el modo en el que actúa con respecto a los aportes procedentes de las precipitaciones de lluvia, ya que la infiltración de aguas procedentes de fusión nival en el suelo tiene efectos más continuados y prolongados que cuando los aportes proceden de la lluvia (Horton, 1938; 1945; Wieczorek y Glade, 2005) permitiendo el desarrollo de episodios de mayor duración (Morton y Campbell, 1974).

Aunque la mayor parte de las inestabilidades se dieron durante la segunda tregua, debemos considerar el papel de los aportes iniciales del deshielo como preparadores del material. Estos venían produciéndose ya desde la primera tregua (20 de febrero), durante el primer conato de deshielo que, en realidad, había sido fruto de la interrupción momentánea de las precipitaciones más que de un aumento notable de las temperaturas que, realmente, no se produjo. Los aportes de agua de fusión durante un periodo más o menos prolongado (de entre 2 y 6 días) bastarían para preparar el material pues el agua dispone del tiempo necesario para infiltrarse en los materiales, por ejemplo si son margas o arcillas para hacerlas plásticas, y desencadenar el movimiento (Starkel, 1976). De este modo, tras la finalización de la primera nevada se dieron ya las primeras inestabilidades, pero fue tras la segunda, cuando la subida de las temperaturas acentuó los procesos de deshielo y el material se halló completamente saturado, cuando el curso del episodio de movimientos en masa se aceleró - acumulándose hasta 21 eventos antes de comenzar la tercera nevada-. La sobresaturación del material instalado sobre aquellos lugares en los que había cierta pendiente, generó la pérdida de cohesión del paquete detrítico, que tendió a movilizarse por imperativo de la gravedad. El momento álgido coincidió además con las precipitaciones de lluvia, responsables de acentuar el proceso de fusión. A partir de este momento, la relación entre el aumento de eventos y la subida de temperatura, aunque sigue existiendo, se debilita, produciéndose un número mucho menor de movimientos durante la tercera tregua. La razón podría ser el gran número de inestabilidades acumuladas desde el inicio de los temporales, y la 
consiguiente pérdida de sedimentos que ya se ha producido. Por otra parte, el hecho de que la mayor parte de esos eventos hayan sido deslizamientos, en los que la pérdida de suelos es especialmente importante, explicaría que, en lo sucesivo, el número de movimientos en masa vaya en descenso a pesar de la continuidad de los aportes de agua.

\subsection{La importancia de los condicionantes}

Si bien consideramos que la fusión nival funcionó como agente desencadenante casi en exclusiva en el episodio de 1888, otros factores combinados entre sí actuaron como condicionantes, siendo frecuente que los movimientos en masa tengan un solo desencadenante y varios agentes causales (Varnes, 1978). En primer lugar debemos considerar la litología del sustrato: en las rocas sedimentarias las discontinuidades más importantes se producen en los planos de estratificación, siendo la presencia de estos mucho más acentuada en las formaciones de caliza tableada, areniscas y/o cuarcitas. Tanto las cuarcitas como las areniscas favorecen la acumulación de grandes paquetes de material que se pueden llegar a movilizar y re-depositar, tal como sucede por ejemplo con la Cuarcita de Barrios (Ordovícico inferior), formación ampliamente distribuida en el territorio del Macizo que, además, suele ser objeto de una densa fracturación, la cual permite la circulación del agua y la consiguiente disgregación de los materiales (Gutiérrez et al., 2008). Teniendo estos factores en cuenta, en el sur del Macizo, especialmente en el sector centro-oriental y en los Picos de Europa, allí donde la pendiente se acentúa encontramos áreas especialmente susceptibles a los desprendimientos rocosos. En cuanto a los deslizamientos, flujos y movimientos de tipología mixta, suceden con la mayor frecuencia en áreas de fuerte pendiente en las que el sustrato lo componen formaciones de edad mesozoica de arenisca y arena, así como limo y arcilla, sobre todo cuando están cubiertas por formaciones superficiales clásticas con abundante matriz arcillosa. Por tanto las áreas más susceptibles a este tipo de inestabilidades se encuentran en el centro del Macizo, en la Cobertera Mesozoico Terciaria y en la Cuenca Carbonífera Central (Marquínez et al., 2003). Si bien en el episodio de 1888 la mayor parte de las inestabilidades se dieron sobre sustratos que favorecen este tipo de sucesos afectando en mayor medida a la Cuenca Carbonífera Central, precisamente una de las zonas más susceptibles en el Macizo, debemos considerar lo extraño de su ausencia en otras áreas. Por ejemplo en la Cobertera MesozoicoTerciaria -que abarcaría el centro-norte de la región asturiana-, no se documenta ni un solo evento. Lo mismo ocurriría en la montaña del suroccidente, donde sólo se documenta uno, o en la zona centro-oriental coincidente con los concejos montañosos de Caso, Ponga y los situados en los Picos de Europa, donde sólo se documentan dos. En la vertiente sur del Macizo, en León, sólo tenemos noticia de uno, no habiéndose producido inestabilidades, supuestamente, en ninguno de los puertos de montaña que comunican ambas provincias (exceptuando Pajares). Además, dentro de la propia Cuenca Carbonífera Central, las inestabilidades se focalizaron en el concejo de Lena y 
no se notificó ninguna en la cuenca media del Nalón, una zona donde se desarrollan este tipo de movimientos en masa de forma recurrente (Domínguez-Cuesta et al., 2007).

En cuanto a la actividad antrópica, esta parece haber tenido un peso especial en el caso que nos ocupa. Los movimientos en masa, en ocasiones, fueron provocados directa o indirectamente por la acción humana, bien durante el transcurso de los temporales de nieve, bien por las acciones desarrolladas en el terreno de forma previa a los mismos. En 24 de los 36 movimientos documentados se habían producido alteraciones recientes - menos de 5 años antes- del relieve. Excepto en dos casos, todas estas modificaciones se correspondieron con el mismo acontecimiento: la construcción del trazado ferroviario entre Gijón y León cuyo último tramo, correspondiente a la Rampa de Pajares, fue inaugurado en 1884. Los otros dos se produjeron en el ramal de Oviedo a Trubia, inaugurado en 1883. En los años previos a 1888 se multiplicó en estas zonas la construcción de trincheras, terraplenes y taludes, generándose acumulaciones en forma de escombreras y realizándose importantes talas en áreas aledañas (Figura 8). Todos estos cambios afectaron a espacios en los que, de otro modo, tal vez no se hubieran producido estos eventos; por ejemplo cinco de los 36 movimientos afectaron a lugares ocupados por depósitos aluviales, donde no es frecuente que se den (Marquínez et al., 2003). En los cinco casos se trataba de espacios recientemente transformados para el paso del ferrocarril.

Figura 8. Imágenes tomadas durante la construcción de la rampa de pajares, a principios de la década de 1880. En ellas observamos los movimientos de tierras -desmontes, trincheras, terraplenes-, así como las talas realizadas durante la misma
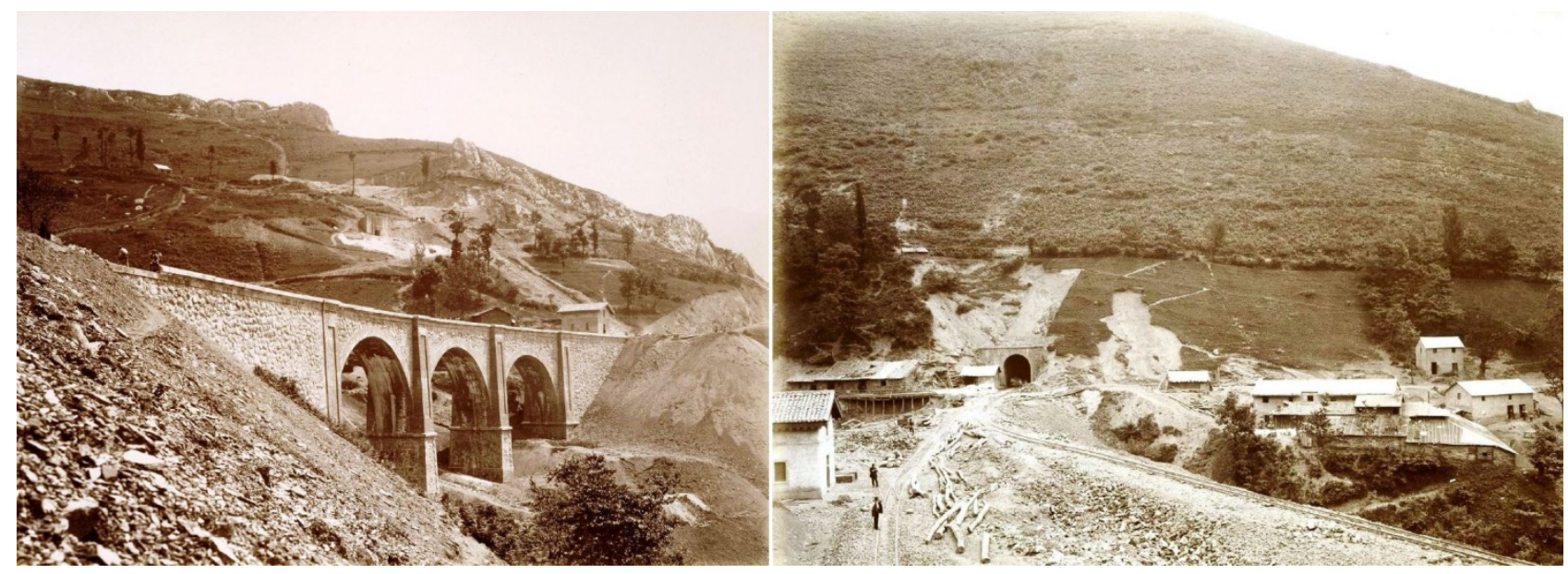

Fuente: Biblioteca Digital Hispánica

Esto permite pensar que, las modificaciones que se habían practicado en la topografía y la vegetación, fueron fundamentales a la hora de condicionar la ocurrencia de inestabilidades, tal como sucede en otros espacios de la montaña media peninsular, donde se ha comprobado que las actividades humanas pueden actuar como condicionante para el desarrollo de movimientos en masa 
(García-Ruiz et al., 2004). En otros casos, como el del evento que afectó a Murias de Pontarás, queda probada también la intervención antrópica como uno de los desencadenantes que actuaron. En primer lugar sabemos que el contenido del movimiento en masa era fundamentalmente de tierra y que fluía como una corriente de agua, lo que nos lleva a pensar que pudo haberse tratado de un flujo, o bien de un deslizamiento que rápidamente se transformase en flujo tal como Varnes (1978) sugiere que puede suceder. Los hallazgos realizados durante el trabajo de campo sostienen también esta idea, ya que el área cóncava que pudo ser identificada se correspondería con una cicatriz en el punto en que arrancó el movimiento, en el que la formación superficial, compuesta fundamentalmente por pequeños fragmentos de pizarra embebidos en una matriz arcillosa, supone la composición ideal para alimentar una colada de barro si los aportes de agua son suficientes para preparar el material (Figura 7). La fusión de la importante capa de nieve depositada tras las dos primeras nevadas, iniciada con el ascenso de las temperaturas una semana antes del desencadenamiento, se habría visto acelerada por las precipitaciones de lluvia producidas el día previo. En el desencadenamiento parecen haberse combinado dos agentes: la infiltración de agua procedente de una fusión masiva, acelerada por los aportes de lluvia, y la actividad humana concretamente el intento de evacuación del agua que inundaba una propiedad- que facilitó la pérdida de cohesión de la masa, ya sobrecargada. En estos casos, la actividad humana es considerada desencadenante último (McSaveney, 1989).

También debemos destacar la importancia de la existencia de depósitos relacionados con movimientos previos, ya que algunos de los movimientos documentados se produjeron de forma recurrente, y al menos dos inestabilidades se habían iniciado ya en años anteriores. Es común que, cuando se ha producido un movimiento de ladera que da lugar a acumulaciones de material suelto con morfología irregular, se generen tramos de fuerte pendiente y zonas escalonadas en las que los materiales pueden resultar fácilmente removilizados (Marquínez, 2003).

\subsection{Impacto territorial, socioeconómico y a mbiental}

Los movimientos en masa fueron documentados, en su mayoría, a lo largo del trazado de la vía férrea entre León y Gijón, donde ocasionaron el mayor número de pérdidas materiales derivadas de los numerosos retrasos e interrupciones que se dieron en el tráfico de mercancías y pasajeros. Este trazado era por entonces de vital importancia económica para ambas provincias, especialmente para Asturias - por ser la principal vía de comunicación con el exterior-. Esto explica que la mayor parte de los eventos (21) se documentasen en Lena, el municipio de montaña más elevado de cuantos atravesaba el trazado férreo, y el que asumía un mayor porcentaje del kilometraje. Hemos de tener en cuenta el gran interés que despertaba el restablecimiento de las comunicaciones, hecho que se vio retrasado por los muchos desprendimientos y deslizamientos que afectaron a la vía, incluso tras la retirada de la nieve. Esto hizo que la atención de toda la provincia se centrara en el trazado ferroviario y, por extensión, en el concejo de Lena, donde los principales periódicos 
enviaron por unas semanas a sus corresponsales. Tan sólo seis de los 36 sucesos documentados, los producidos en Cangas del Narcea, Llanes, Riosa, Caso y Peñamellera Alta, no afectaron al concejo de Lena o al trazado ferroviario. En este sentido también es llamativo el hecho de que, tal como se ha expuesto en el apartado anterior, ciertas zonas que por su sustrato litológico y por su relieve intrincado son especialmente susceptibles de ser afectadas por estos eventos, no parecen haber experimentado ninguno durante este episodio. En la vertiente sur del Macizo, en León, sólo tenemos noticia de uno, no habiéndose producido inestabilidades, supuestamente, en ninguno de los puertos de montaña que comunican ambas provincias, exceptuando Pajares.

Todo apunta a una importante desatención a este tipo de eventos allí donde los daños no fuesen del interés de toda la provincia o los efectos no fuesen espectaculares, como en el caso del deslizamiento de Flogueraxú, por ejemplo. E incluso debemos recordar que, el único fallecimiento a consecuencia de este episodio de movimientos en masa del que tenemos conocimiento no fue reflejado por ningún medio de prensa, figurando sólo en el registro parroquial. Por otro lado, debemos tener en cuenta también la gran cantidad de información difusa relativa al número de eventos, lugares afectados y daños derivados que ha debido ser desechada en el transcurso de esta investigación, por ser imposible de concretar o cuantificar. Entre las dificultades derivadas del uso de los archivos de prensa para el estudio de los riesgos geomorfológicos, el subregistro, el sesgo geográfico y la falta de concreción destacan como los principales problemas (GarcíaHernández et al., 2017). Por tanto, en este caso, parece más que probable que, el número de eventos que se registraron y en definitiva el impacto territorial de este episodio, haya resultado claramente mermado con respecto a sus verdaderas dimensiones.

Por último, a parte de los daños socioeconómicos directos e indirectos generados por la destrucción de viviendas, construcciones anejas y vías de comunicación, debemos considerar la pérdida de suelos que afectó a numerosas fincas rústicas, así como el impacto de la carga sedimentaria arrastrada por el agua de fusión, que se vertió durante semanas en los ríos del Macizo. El arrastre de bloques y el incremento en el lavado de finos (Caine, 1992), así como la pérdida de suelos y la producción de sedimentos derivadas de la fusión nival (Strömquist, 1985), pueden afectar a la calidad del agua de los ríos mediante el aumento de la carga sedimentaria de los mismos, saturando espacios represados, imposibilitando que sea usada con ciertos fines y constituyendo, en definitiva, uno de los efectos ambientales más negativos de los movimientos en masa (Schuster, 1996).

\section{Conclusiones}

El proceso de fusión nival fue el principal causante, y el agente desencadenante, del episodio de movimientos en masa originado en las treguas que se sucedieron durante los temporales de febrero, marzo y abril de 1888. La subida súbita de las temperaturas tras un periodo de intensas 
nevadas, junto con un evento de lluvia sobre nieve que aceleró el proceso de fusión, dio lugar a grandes aportes de agua que saturaron las formaciones superficiales y penetraron en las grietas abiertas en el roquedo, desencadenando un episodio de 36 movimientos en masa en el que primaron los deslizamientos (15), seguidos por los desprendimientos de rocas (5), movimientos mixtos (4) y flujos (4). El resto de movimientos (8) no han podido ser identificados.

La actividad antrópica ha resultado ser uno de los principales condicionantes en este episodio, de modo que las modificaciones realizadas para la construcción de los trazados del ferrocarril durante los años previos al episodio - década de 1880_, resultaron cruciales para determinar la ocurrencia de sucesos en los espacios ocupados por estos trayectos. La actividad antrópica funcionó también, en algún caso, como desencadenante último.

Las principales consecuencias desde el punto de vista socioeconómico y ambiental fueron los retrasos en las comunicaciones, los daños generados en viviendas y otras construcciones, los desalojos forzados de ciertas poblaciones, la pérdida de suelos en fincas y tierras de labor, así como el impacto sobre los cursos de agua, que vieron notablemente aumentada su carga sedimentaria durante el episodio de movimientos en masa.

La cobertura de los hechos de 1888 por parte de la prensa experimentó un fuerte sesgo geográfico, de modo que se tendió a reflejar fundamentalmente lo ocurrido en un solo sector -el atravesado por las principales vías de comunicación con el exterior-, ignorándose lo sucedido en la mayor parte del territorio del Macizo. En definitiva, la presencia de ciertas infraestructuras y especialmente del trazado del ferrocarril, en el que se produjeron la mayor parte de los cortes de comunicaciones, condicionó la existencia de noticias. De este modo, los datos que manejamos en cuanto a número de eventos, pérdidas humanas y materiales deben ser considerados como mínimos y están, probablemente, muy lejos de alcanzar la cifra real. En este sentido cabe destacar que, aunque los archivos de prensa han sido la guía principal para el desarrollo de esta investigación, la información recogida tiene que ser complementada siempre con la obtenida a partir de otras fuentes y técnicas -entrevistas, trabajo de campo, evidencias geomorfológicas-, debido a la frecuente aparición de errores e inexactitudes, los vacíos en la información y el sesgo geográfico. 


\section{Bibliografía}

Barriendos, M. (1997). Climatic variations in the Iberian Peninsula during the late Maunder Minimum (AD 1675-1715): an analysis of data from rogation ceremonies. The Holocene, 7, 105-111.

Benito, G., y Thorndycraft, V. R. (2004). Systematic, Palaeoflood and Historical Data for the Improvement of Flood Rrisk Estimation: Methodological Guidelines. Madrid: CSIC.

Caine, N. (1992). Sediment transfer on the floor of the Martinelli snowpatch, Colorado front Range, U.S.A. Geografiska Annaler: Series A, Physical Geography, 74, 133-144.

Chleborad, A. F. (1997). Temperature, Snowmelt, and the Onset of Spring Season Landslides in the Central Rocky Mountains. Denver: U.S. Geological Survey.

Decaulne, A., Sæmundsson, P., y Petursson, O. (2005). Debris Flow Triggered by Rapid Snowmelt: A Case Study in The Gleiðarhjalli Area, Northwestern Iceland. Geografiska Annaler: Series A, Physical Geography, 87, 487-500.

Degraff, J. V., Mckean, J., Watanabe, P. E., y Mccaffery, W. F. (1984). Landslide activity and ground-water conditions: insights from a road in the Central Sierra Nevada, California. Transportation Research Record, 965, 32-37.

Devoli, G., Morales, A., y Høeg, K. (2007). Historical landslides in Nicaragua: collection and analysis of data. Landslides, 4, 5-18.

Domínguez-Cuesta, M. J., Jiménez-Sánchez, M., y Rodríguez-García, A. (1999). Press archives as temporal records of landslides in the North of Spain, relationships between rainfall and instability slope events. Geomorphology, 30, 125-132.

Domínguez-Cuesta, M. J., Jiménez-Sánchez, M., y Berrezueta, E. (2007). Landslides in the Central Coalfield (Cantabrian Mountains, NW Spain): Geomorphological features, conditioning factors and methodological implications in susceptibility assessment. Geomorphology, 89, 358-369.

Elliott, A. H., y Kirschbaum, M. J. (2007). The Preliminary Landslide History Database of Utah, 1850-1978. Utah: Utah Geological Survey.

Ericsson, J. (1991). Las Tormentas: de antiguas creencias a la moderna meteorología. Madrid: McGraw-Hill/Interamericana de España.

Fernández-lglesias, E., Menéndez-Duarte, R., y Santos-Alonso, R. (2010). La cornisa cantábrica. Ejemplo de red hidrográfica dominada por ríos en roca. En J. A. Ortega y J. J. Durán (Eds.), Patrimonio geológico: los ríos en roca de la Península Ibérica (pp. 193-210). Madrid: Instituto Geológico y Minero de España.

García-Hernández, C., Ruiz-Fernández, J., Sánchez de Posada, C., y Poblete, M. A. (2014). El impacto del episodio avalanchoso de 1888 en el Macizo Asturiano, a través de la prensa. En A. 
Gómez-Ortiz, F. Salvador, M. Oliva y M. Salvà (Eds.), Avances, métodos y técnicas en el estudio del periglaciarismo (pp. 55-64). Barcelona: Universidad de Barcelona.

García-Hernández, C., Ruiz-Fernández, J., Sánchez-Posada, C., Pereira, S., Oliva, M., y Vieira, G. (2017). Reforestation and land use change as drivers for a decrease of avalanche damage in mid latitude mountains (NW Spain). Global and Planetary Change, 153, 35-50.

García-Hernández, C., Ruiz-Fernández, J., Sánchez-Posada, C., Pereira, S., y Oliva, M. (2018). An extreme event between the Little Ice Age and the 20th Century: the snow avalanche cycle of 1888 in the Asturian Massif (Northern Spain). Cuadernos de Investigación Geográfica. doi: http://dx.doi.org/10.18172/cig.3386.

García-Ruiz, J., Chueca, A., y Julián, J. (2004). Los movimientos en masa del Alto Gállego. En J. L. Peña, L. A. Longares y M. Sánchez (Eds.), Geografía Física de Aragón. Aspectos generales y temáticos (pp. 141-152). Zaragoza: Universidad de Zaragoza e Institución Fernando el Católico.

Glancy, P. A., y Bell, J. W. (2000). Landslide-induced flooding at Ophir Creek, Washoe County, western Nevada, May 30, 1983. U.S. Geological Survey Professional, Reston, Virginia, 1617.

Gokceoglu, C., Sonmez, H., Nefeslioglu, H. A., Duman, T. Y., y Can, T. (2005). The 17 March 2005 Kuzulu landslide (Sivas, Turkey) and landslide-susceptibility map of its near vicinity. Engineering Geology, 81, 65-83.

Gómez, A., Palacios, D., Luengo, E., Tanarro, L.M., Schulte, L., Ramos, M., y Salvador, F. (2002). Inestabilidad de taludes y cubierta nival en áreas marginales de permafrost. El caso de la pared norte del Veleta (Sierra Nevada, España). Revista de Geografía, 1, 35-56.

González-Trueba, J. J., y Serrano, E. (2010). La nieve en los Picos de Europa: Implicaciones geomorfológicas y ambientales. Cuadernos de Investigación Geográfica, 36(2), 61-84.

Gutiérrez, M., Pando, L., y García-Ramos, J. C. (2008). Procesos y productos de alteración de formaciones rocosas en Asturias y su repercusión socio-económica. Boletín Geológico y Minero, 119(2), 211-230.

Harr, R. D. (1981). Some characteristics and consequences of snowmelt during rainfall in western Oregon. Journal of Hidrology, 53, 277-304.

Horton, R. E. (1938). Phenomena of the contact zone between the ground surface and a layer of melting snow. Associacion Internationale d'Hydrologie Scientifique, 244, 545-561.

Horton, R. E. (1945). Infiltration and runoff during the snow-melting season, with forest-cover. Transactions American Geophysical Union, 26, 59-68.

Huschke, R. W. (1959). Glossary of Meteorology. Boston: American Meteorological Society. 
Jiménez-Sánchez, M., Farias, P., Rodríguez-García, A., y Menéndez Duarte, R.A. (1999). Landslide development in a coastal valley in Northern Spain: Conditioning factors and temporal occurrence. Geomorphology, 30, 115-123.

Kocin, P. J. (1983). An Analysis of the "Blizzard of '88". Bulletin of the American Meteorological Society, 64, 1258-1272.

Mcsaveney, M. J., y Whitehouse, I. E. (1989). Anthropic erosion of mountain land in Canterbury. New Zealand Journal of Ecology, 12, 151-163.

Marquínez, J., Menéndez, R., Lastra, J., Fernández-lglesias, E., Jiménez-Alfaro González, B., Wozniak, E., Fernández, S., García-Roces, J., García-Manteca, P., Álvarez, M.A., Lobo Del Corro, T., y Adrados, L. (2003). Riesgos Naturales en Asturias. Oviedo: KRK.

Morton, D. M., y Campbell, R. H. (1974). Spring mudflows at Wrightwood, Southern California. Quarterly Journal of Engineering Geology and Hydrogeology, 7, 377-384.

Muntán, E., García, C., Oller, P., Martí, G., García, A., y Gutiérrez, E. (2009). Reconstructing snow avalanches in the Southeastern Pyrenees. Natural Hazards and Earth System Science, 9, 1599-1612.

Muñoz, J. (1982). Geografía Física. El relieve, el clima y las aguas. En F. Quirós (Dir.), Geografía de Asturias, tomo / (pp. 1-271). Salinas: Ayalga Ediciones.

Naudet, V., Lazzari, M., Perrone, A., Loperte, A., Piscitelli, S., y Lapenna, V. (2008). Integrated geophysical and geomorphological approach to investigate the snowmelt-triggered landslide of Bosco Piccolo village (Basilicata, southern Italy). Engineering Geology, 98, 156-167.

Petley, D. (2012). Global patterns of loss of life from landslides. Geology, 40(10), 927-930.

Podolskiy, E., Izumi, K., Suchkov, V., y Eckert, N. (2014). Physical and societal statistics for a century of snow-avalanche hazards on Sakhalin and the Kuril Islands (1910-2010). Journal of Glaciology, 60, 409-430.

Popescu, M. (1996). From landslide causes to landslide remediation. En Procedings of the 7th International Symposium on Landslides (pp. 75-96). Trondheim, Norway.

Pulgar, J. A., Alonso, J. L., Espina, R. G., y Marín, J. A. (1999). La deformación alpina en el basamento varisco de la Zona Cantábrica. Trabajos de Geología, 21, 283-294.

Raetzo, H., Lateltin, O., y Tripet, J. P. (2002). Landslides and evaluation of triggering factors, hazard assessment practice in Switzerland. En J. Rybar, J. Stemberk y P. Wagner (Eds.), Proceedings of the 1st European conference on landslides (pp. 455-460). Rotterdam: Balkema. 
Rossi, M., Witt, A., Guzzetti, F., Malamud, B., y Peruccacci, S. (2010). Analysis of historical landslide time series in the Emilia-Romagna region, northern Italy. Earth Surface Processes and Landforms, 35, 1123-1137.

Rulli, M. C., Gobattoni, F., y Santini, M. (2013). GALLIUS: Geomorphohydrological Model for Landslide Initiation Under Snowmelting. En C. Margottini, P. Canuti y K. Sassa (Eds.), Landslide Science and Practice (pp. 409-415). Springer: Berlin, Heidelberg.

Ruiz-Fernández, J., Poblete, M. A., y García-Hernández, C. (2014). Características morfoclimáticas y procesos y formas periglaciares actuales en el Macizo Occidental de los Picos de Europa (Cordillera Cantábrica). En A. Gómez-Ortiz, F. Salvador, M. Oliva y M. Salvà (Eds.), Avances, métodos y técnicas en el estudio del periglaciarismo (pp. 91-103). Barcelona: Universidad de Barcelona.

Ruiz-Fernández, J. (2015). Las formas de modelado glaciar, periglaciar y fluviotorrencial del Macizo Occidental de los Picos de Europa (Cordillera Cantábrica). Boletín de la Asociación de Geógrafos Españoles, 68, 581-587.

Sæmundsson, P., Pétursson, H. G., y Decaulne, A. (2003). Triggering factors for rapid massmovements in Iceland. En D. Rickenman, y C. I. Chen (Eds.), Debris-Flow Hazards Mitigation: Mechanics, Prediction, and Assessment (pp. 167-178). Rotterdam: Millpress.

Santos, R., y Menéndez Duarte, M. (2006). Topographic signature of debris flow dominated channels implications for hazard assessment. En G. Lorenzini, C. A. Brebbia y D. Emmanouloudis (Eds.), Monitoring, Simulation, Prevention and Remediation of Dense and Debris Flows (pp. 301 310). Southampton, Boston: WIT Press.

Schuster, R. L. (1996). Socioeconomic significance of landslides. En A. K. Turner y R. L. Schuster (Eds.), Landslides: Investigation and Mitigation: Special Report, vol. 247 (pp. 12-36). Washington, D.C.: National Academic Press.

Schuster, R. L., y Wieczorek, G. F. (2002). Landslide triggers and types. En J. Rybar, J. Stemberk y P. Wagner (Eds.), Landslides. Procedings of the 7st European Conference on Landslides (pp. 5978). Prague.

Serrano, E., y González Trueba, J. J. (2004). Morfodinámica periglaciar en el grupo Peña Vieja (Macizo Central de los Picos de Europa -Cantabria-). Cuaternario y Geomorfología, 18, 73-78.

STARKEL, L. (1976). The role of extreme (catastrophic) meteorological events in contemporary evolution of slopes. En E. Derbyshire (Ed.), Geomorphology and climate (pp. 203-246). Londres: Wiley.

Strömquist, L. (1985). Geomorphic impact of snowmelt on slope erosion and sediment production. Zeitschrift für Geomorphologie N. F., 29, 129-138. 
Tanarro, L. M., Palacios, D., Zamorano, J. J., y Gómez-Ortiz, A. (2010). Cubierta nival, permafrost y formación de flujos superficiales en el talud detrítico de alta montaña (Corral del Veleta, Sierra Nevada. España). Cuadernos de Investigación Geográfica, 36, 39-59.

Vadillo, J. A. (1987). Formas y procesos en la evolución de vertientes de la Sierra de la Demanda (Sistema Ibérico). Cuadernos de Investigación Geográfica, 13, 9-153.

Valcárcel, M, y Carrera, P. (2010). La acción geomorfológica del manto nivoso estacional en la Sierra de Ancares: Vertiente nororiental del Pico Cuiña (León). Cuadernos de Investigación Geográfica, 36, 85-98.

Varnes, D. J. (1978). Slope movement types and processes. En R. L. Schuster y R. J. Krizek (Eds.), Landslides: Analysis and Control, Special Report, vol. 176 (pp. 11-33). Washington, D.C.: National Academic Press.

Wieczorek, G. F. (1996). Landslide triggering mechanisms. En A. K. Turner y R. L. Schuster (Eds.), Landslides: Investigation and Mitigation: Special Report, vol. 247 (pp. 76-90). Washington, D.C: National Academic Press.

Wieczorek, G. F., y Glade, T. (2005). Climatic factors influencing occurrence of debris flows. En M. Jakob y O. Hungr (Eds.), Debris-flow hazards and related phenomena (pp. 325-362). Chichester, Springer-Praxis. 